Supplement of Atmos. Chem. Phys., 21, 13763-13795, 2021

https://doi.org/10.5194/acp-21-13763-2021-supplement

(C) Author(s) 2021. CC BY 4.0 License.

(c) (1)

Supplement of

\title{
The semiannual oscillation (SAO) in the tropical middle atmosphere and its gravity wave driving in reanalyses and satellite observations
}

Manfred Ern et al.

Correspondence to: Manfred Ern (m.ern@fz-juelich.de)

The copyright of individual parts of the supplement might differ from the article licence. 
In the main paper only distributions of the different parameters averaged over multiple years are shown. However, also the distributions for single years contain important information. This is the case because the semiannual oscillation (SAO) undergoes strong interannual variability, and there are peculiarities of the gravity wave driving in certain years. Further, before the year 2004 no MLS data are assimilated in the MERRA-2 reanalysis. Therefore, the distributions for the single years are important to show that MERRA-2 simulates a reasonable SAO also in the years before 2004. The reasonable SAO in the early MERRA-2 years is likely an effect of the parameterized gravity wave drag in MERRA-2 that was tuned in a way to simulate a reasonable SAO in all years. This is indicated by the rather low imbalance term shown in Fig. S19. For these reasons, we provide the distributions for the single years 2002 until 2018, as well as the average distributions in this supplement.

\section{The following figures are shown in the supplement:}

Figure S1 shows the local solar times of SABER and TIDI observations at the equator.

Figures S2-S5 show zonal-average zonal wind averaged over $10^{\circ} \mathrm{S}-10^{\circ} \mathrm{N}$ for the four reanalyses ERA-Interim, JRA-55, ERA5, and MERRA-2.

Figure S6 shows a merged zonal wind product that uses ERA-Interim at low altitudes, and, at higher altitudes, zonal wind estimated from MLS observations using the quasi-geostrophic assumption.

Figure S7 shows a merged zonal wind product that uses ERA-Interim at low altitudes, SABER quasi-geostrophic winds at mid altitudes, and TIDI wind observations at high altitudes ("E/S/T-winds"). For details see the main paper.

Further, zonal total gravity wave drag $\bar{X}_{G W}$ was estimated for the four reanalyses. $\bar{X}_{G W}$ comprises the drag of model-resolved waves at zonal wavenumbers $k$ higher than $20\left(\bar{X}_{\text {res }}(k>20)\right)$, gravity wave drag that is parameterized in the model $\left(\bar{X}_{\text {param }}\right)$, and the remaining imbalance $\left(\bar{X}_{\text {imbalance }}\right)$ in the momentum budget that is caused by, for example, data assimilation:

$$
\bar{X}_{G W}=\bar{X}_{\text {res }}(k>20)+\bar{X}_{\text {param }}+\bar{X}_{\text {imbalance }}
$$

Figures S8-S10 show the zonal total gravity wave drag $\bar{X}_{G W}$ for the four reanalyses, and Figs. S12-S14 the model-resolved gravity wave drag $\bar{X}_{\text {res }}(k>20)$. Figures S16-S17 show the parameterized gravity wave drag $\bar{X}_{\text {param }}$ for JRA-55 and MERRA-2, and Figs. S18-S19 the imbalance term $\bar{X}_{\text {imbalance }}$ for JRA-55 and MERRA-2 that contributes to the estimate $\bar{X}_{G W}$ of the total gravity wave drag. For ERA-Interim and ERA-5 $\bar{X}_{\text {param }}$ and $\bar{X}_{\text {imbalance }}$ are not available.

Figure S20 shows SABER absolute gravity wave momentum flux.

Figure S21 shows the SABER proxy "MFz-proxy- $\mid$ GWD|" which is obtained from vertical gradients of SABER absolute gravity wave momentum flux normalized by the negative background density. Under certain assumptions, MFz-proxy- $\mid$ GWD $\mid$ can be used as a proxy for absolute net gravity wave drag.

Figures S22 and S23 show the same as Fig. S21, but values are normalized by the altitude-dependent annual averages.

Similar as Fig. 8 in the main paper, Fig. S24 shows correlations between SABER MFz-proxy- $\mid$ GWD $\mid$ and the vertical gradient of the zonal wind, as well as correlations between SABER MFz-proxy- $\mid$ GWD $\mid$ and absolute zonal wind speed, but for three additional combinations of MFz-proxy- $|\mathrm{GWD}|$ and wind data set.

\section{References:}

Randel, W., Chanin, M.-L., Michaut, C., and the SPARC Reference Climatology Group: SPARC intercomparison of middle atmosphere climatologies, WCRP 116, WMO/TD No. 1142, SPARC report No. 3, 2002.

Randel, W., Udelhofen, P., Fleming, E., Geller, M., Gelman, M., Hamilton, K., Karoly, D., Ortland, D., Pawson, S., Swinbank, R., Wu, F., Baldwin, M., Chanin, M.-L., Keckhut, P., Labitzke, K., Remsberg, E., Simmons, A., and Wu, D. L.: The SPARC intercomparison of middle-atmosphere climatologies, J. Climate, 17, 986-1003, 2004.

Swinbank, R., and Ortland, D. A.: Compilation of wind data for the UARS Reference Atmosphere Project, J. Geophys. Res., 108, 4615, doi:10.1029/2002JD003135, 2003. 

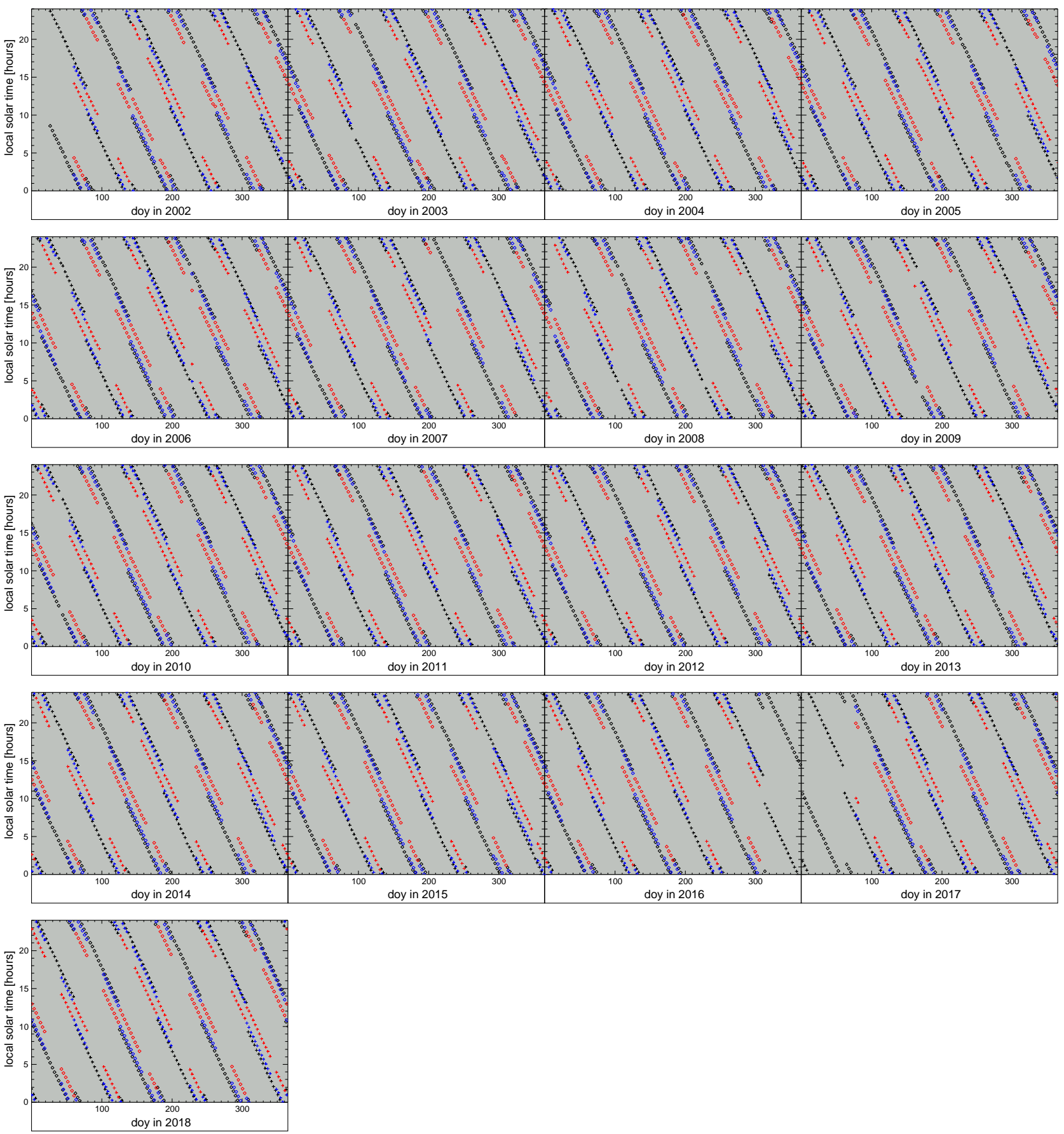

Figure S1. Local solar times of SABER and TIDI observations at the equator for the 2002-2018 time period. Local solar times are given for the following: SABER ascending (black diamonds), SABER descending (black crosses) TIDI warm side ascending (red diamonds), TIDI warm side descending (red crosses), TIDI cold side ascending (blue diamonds), and TIDI cold side descending (blue crosses). 

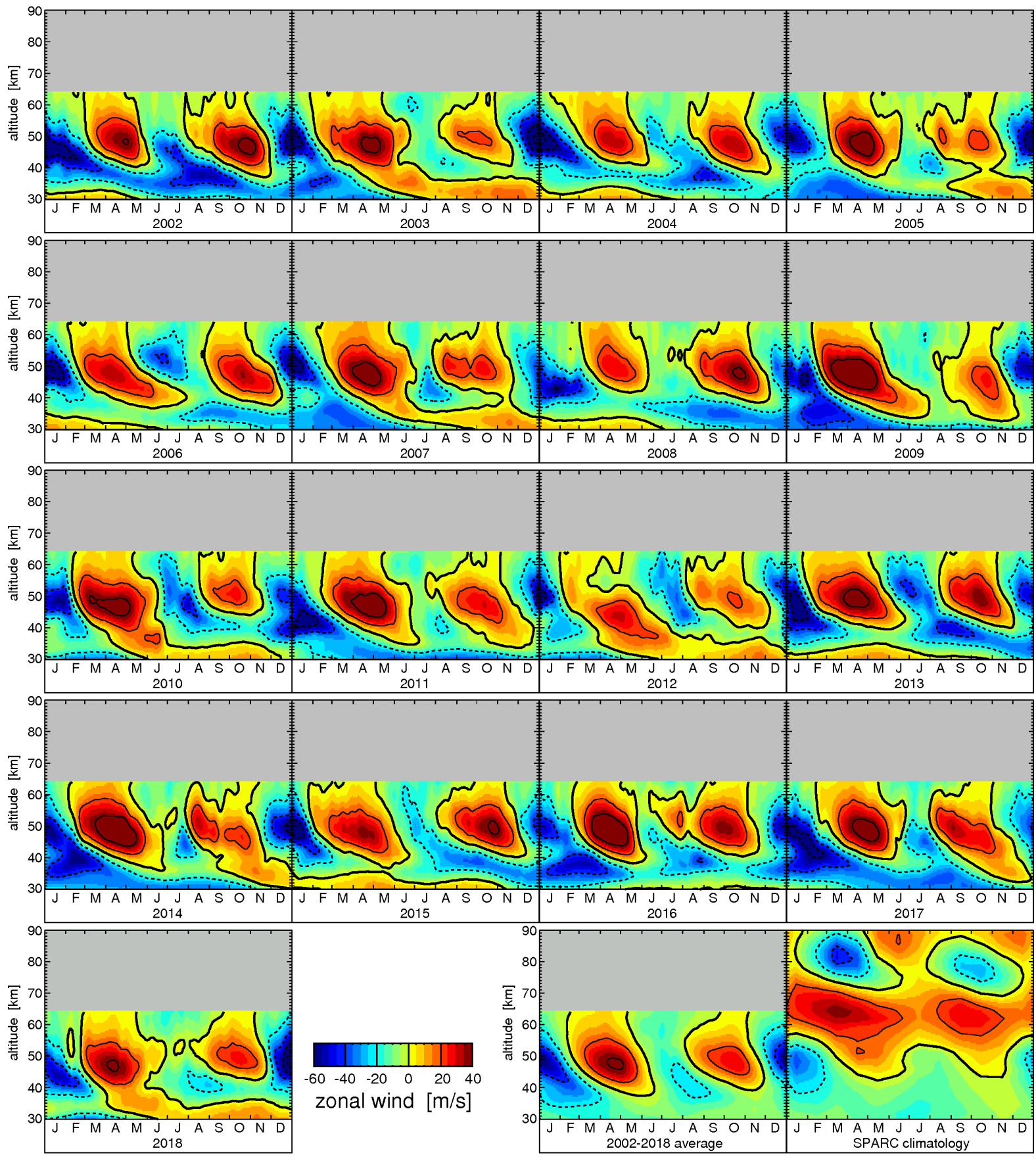

Figure S2. ERA-Interim zonal-average zonal wind averaged over $10^{\circ} \mathrm{S}-10^{\circ} \mathrm{N}$ for the $2002-2018$ time period together with the multi-year mean seasonal cycle over the same period (lower row, middle panel). For comparison the lower right panel shows the corresponding zonal winds of the SPARC climatology (cf. Swinbank and Ortland, 2003; Randel et al., 2002, 2004). Contour line increment is $20 \mathrm{~m} \mathrm{~s}^{-1}$. The zero wind line is highlighted in bold solid, and westward (eastward) winds are indicated by dashed (solid) contour lines. 

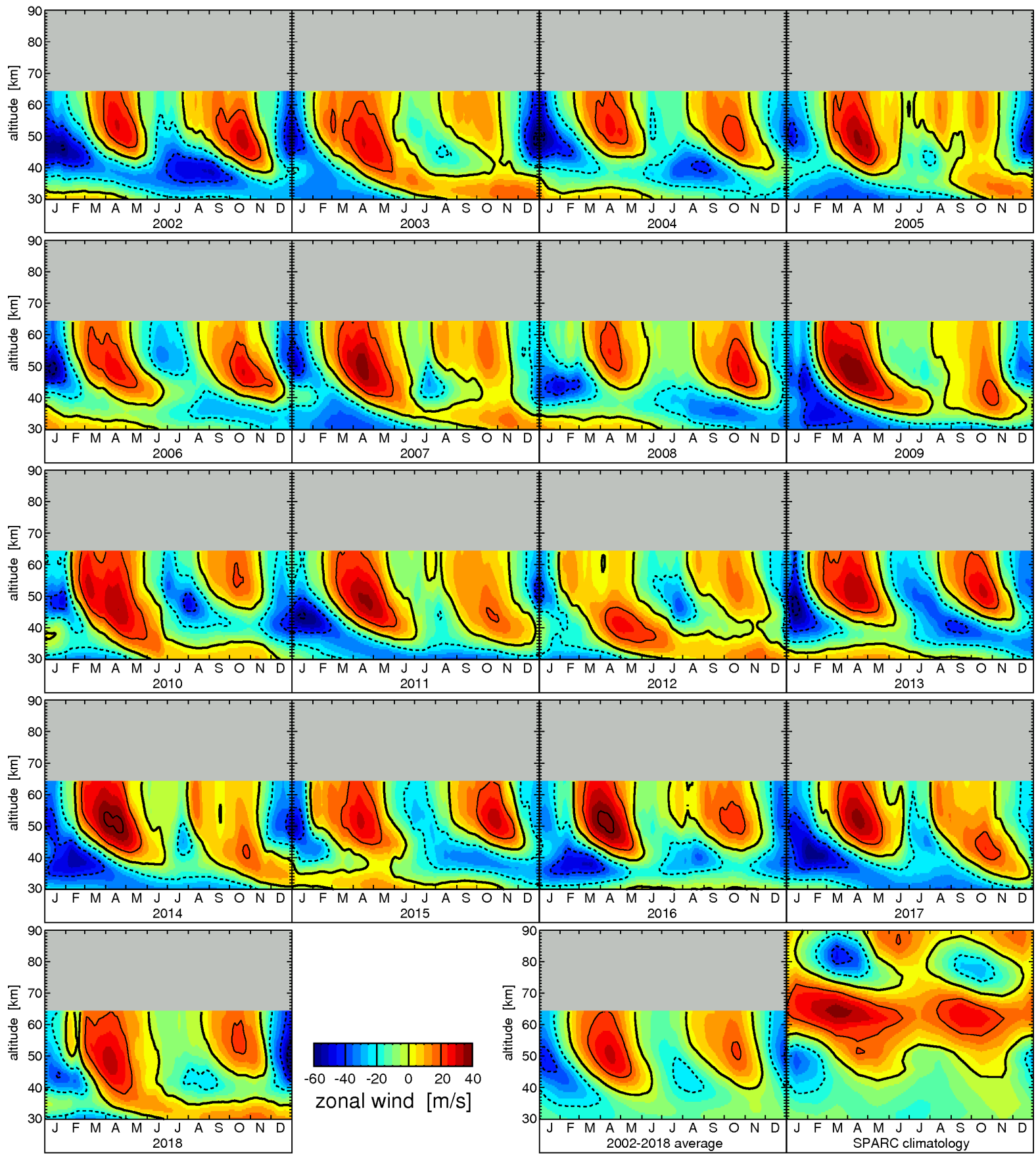

Figure S3. Same as Fig. S2, but zonal-average zonal wind for the JRA-55 reanalysis. 


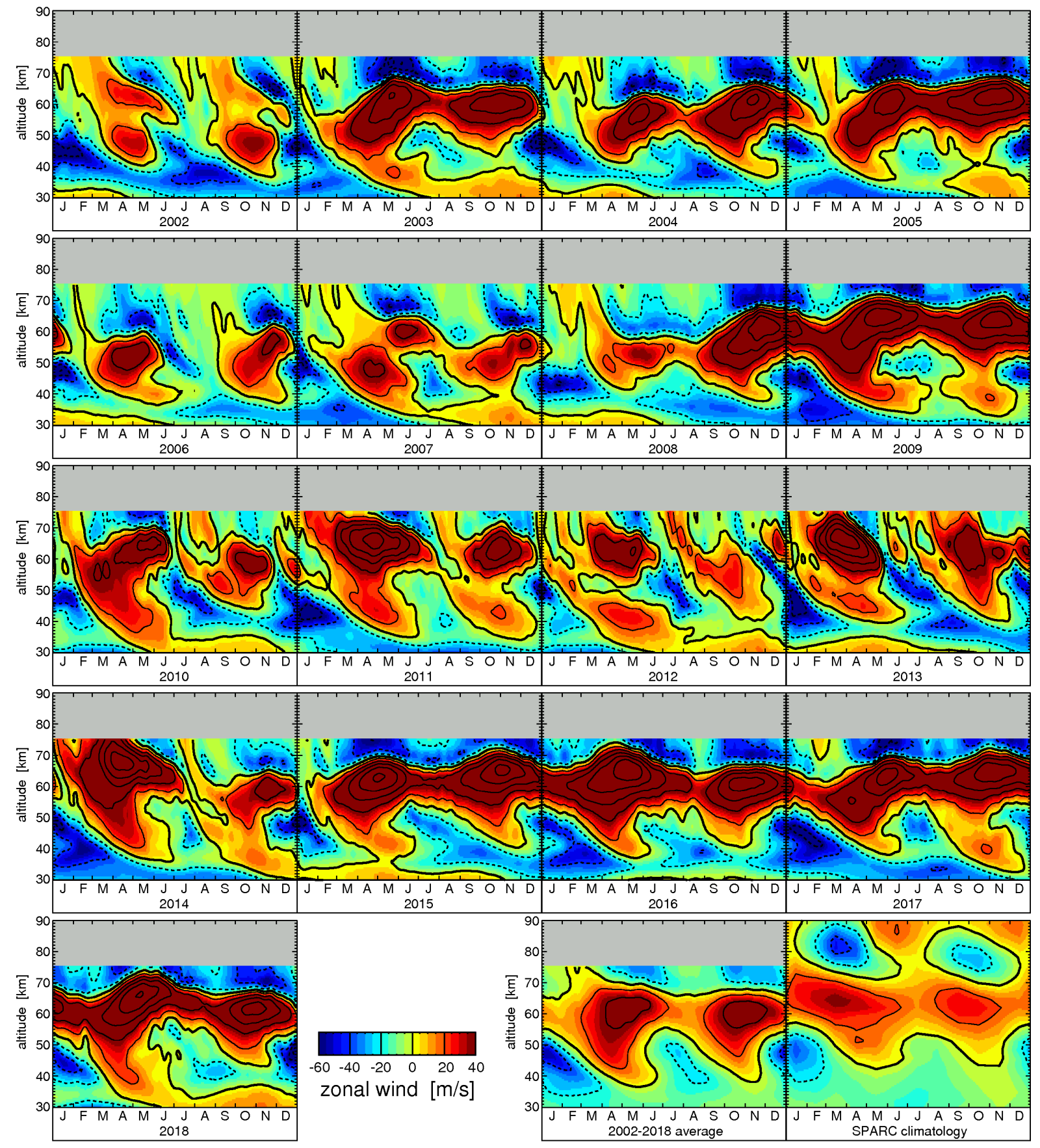

Figure S4. Same as Fig. S2, but zonal-average zonal wind for the ERA-5 reanalysis. 

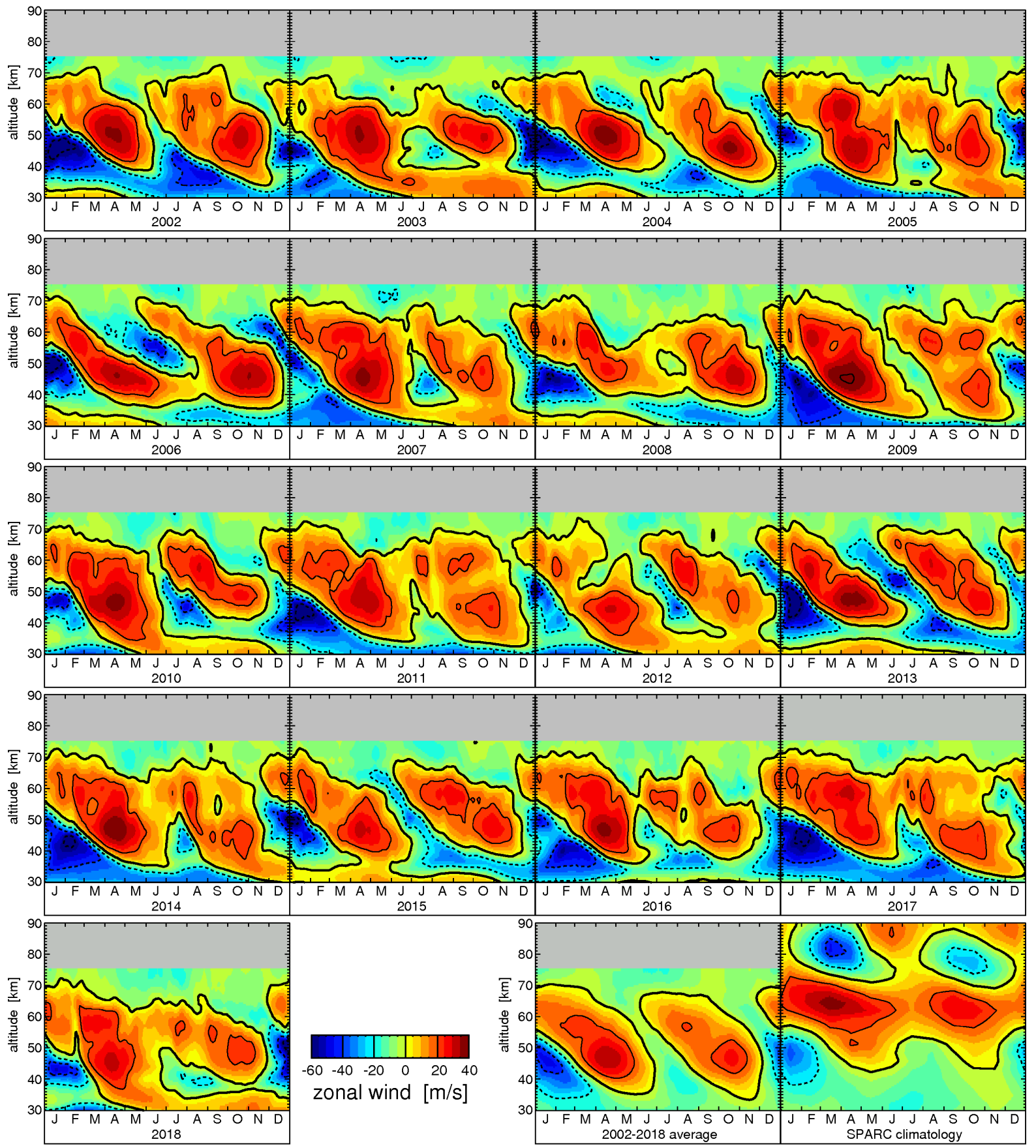

Figure S5. Same as Fig. S2, but zonal-average zonal wind for MERRA-2. 

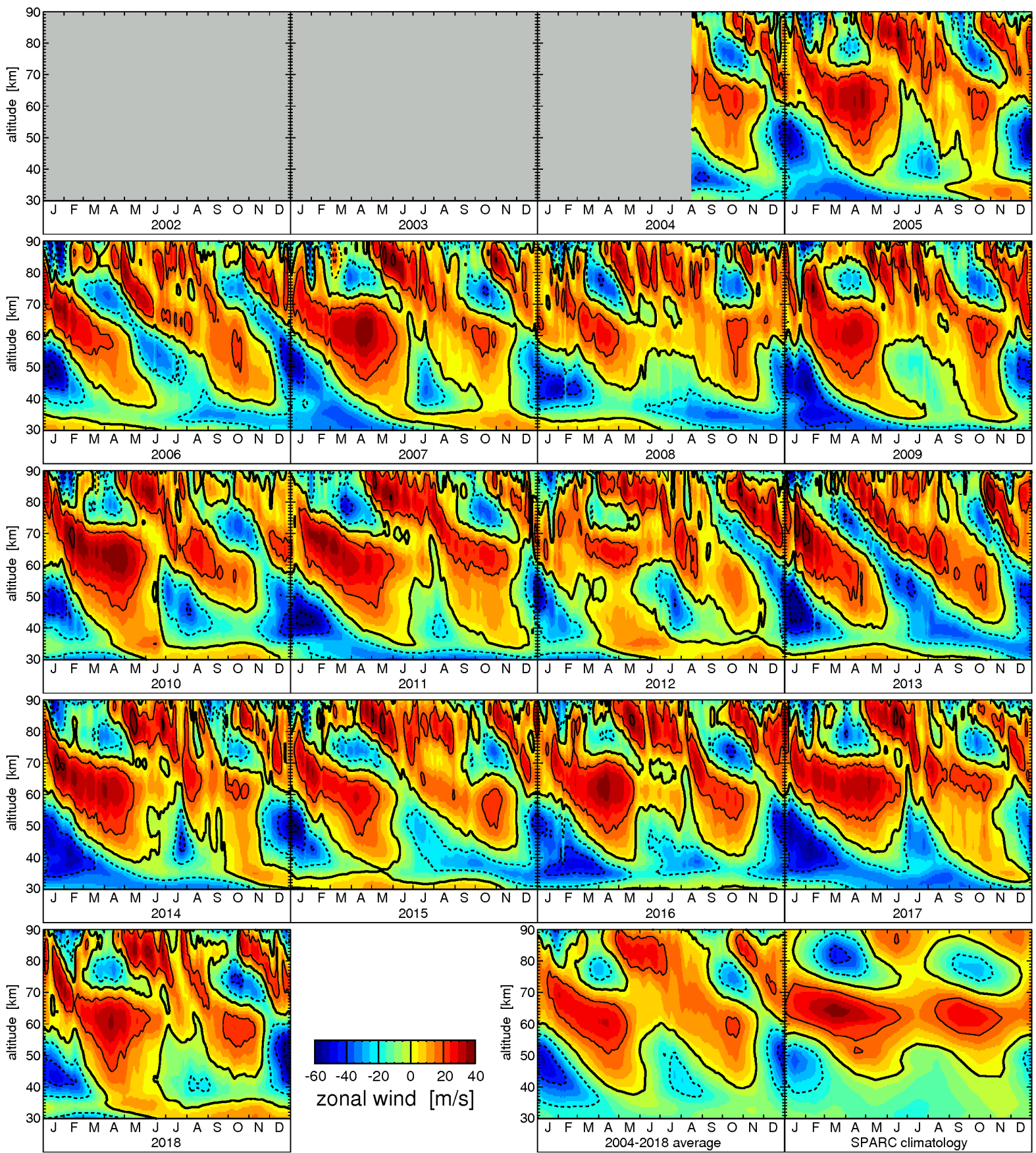

Figure S6. Same as Fig. S2, but for the combined data set of ERA-Interim zonal winds below $35 \mathrm{~km}$ and, at higher altitudes, interpolated MLS quasi-geostrophic zonal winds averaged over the latitude band $10^{\circ} \mathrm{S}-10^{\circ} \mathrm{N}$. At altitudes $35-45 \mathrm{~km}$ a smooth transition between ERAInterim and MLS winds is made. The MLS winds represent an average over both local solar times (ascending and descending orbit nodes are combined). MLS observations started in 2004. Therefore, the panels for 2002 and 2003 are left blank. 

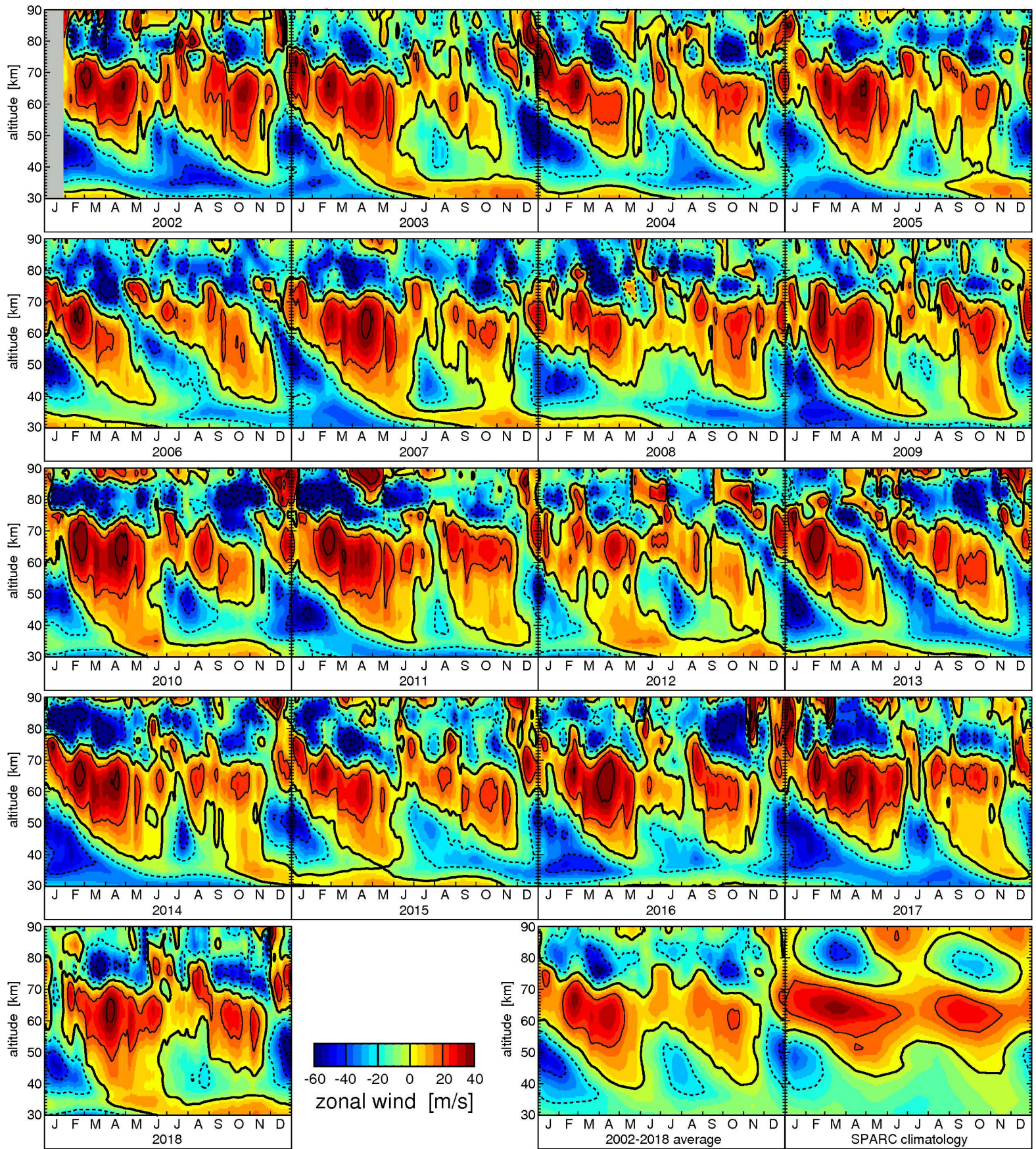

Figure S7. Same as Fig. S2, but for the combined data set (E/S/T-winds) of ERA-Interim zonal winds below $35 \mathrm{~km}$, interpolated SABER quasi-geostrophic zonal winds at altitudes $45-75 \mathrm{~km}$, and a smooth transition between ERA-Interim and SABER winds at altitudes $35-$ $45 \mathrm{~km}$. Winds above $\sim 80 \mathrm{~km}$ are TIDI cold side zonal winds. Several smaller TIDI data gaps are closed by linear interpolation in time. For one larger data gap and in the beginning of 2002 SABER quasi-geostrophic winds are used also above $75 \mathrm{~km}$. Otherwise the data gap between SABER winds at $75 \mathrm{~km}$ and TIDI winds at $80 \mathrm{~km}$ is interpolated. Winds are an average over $10^{\circ} \mathrm{S}-10^{\circ} \mathrm{N}$, and SABER and TIDI winds are an average over ascending and descending orbit branches. 

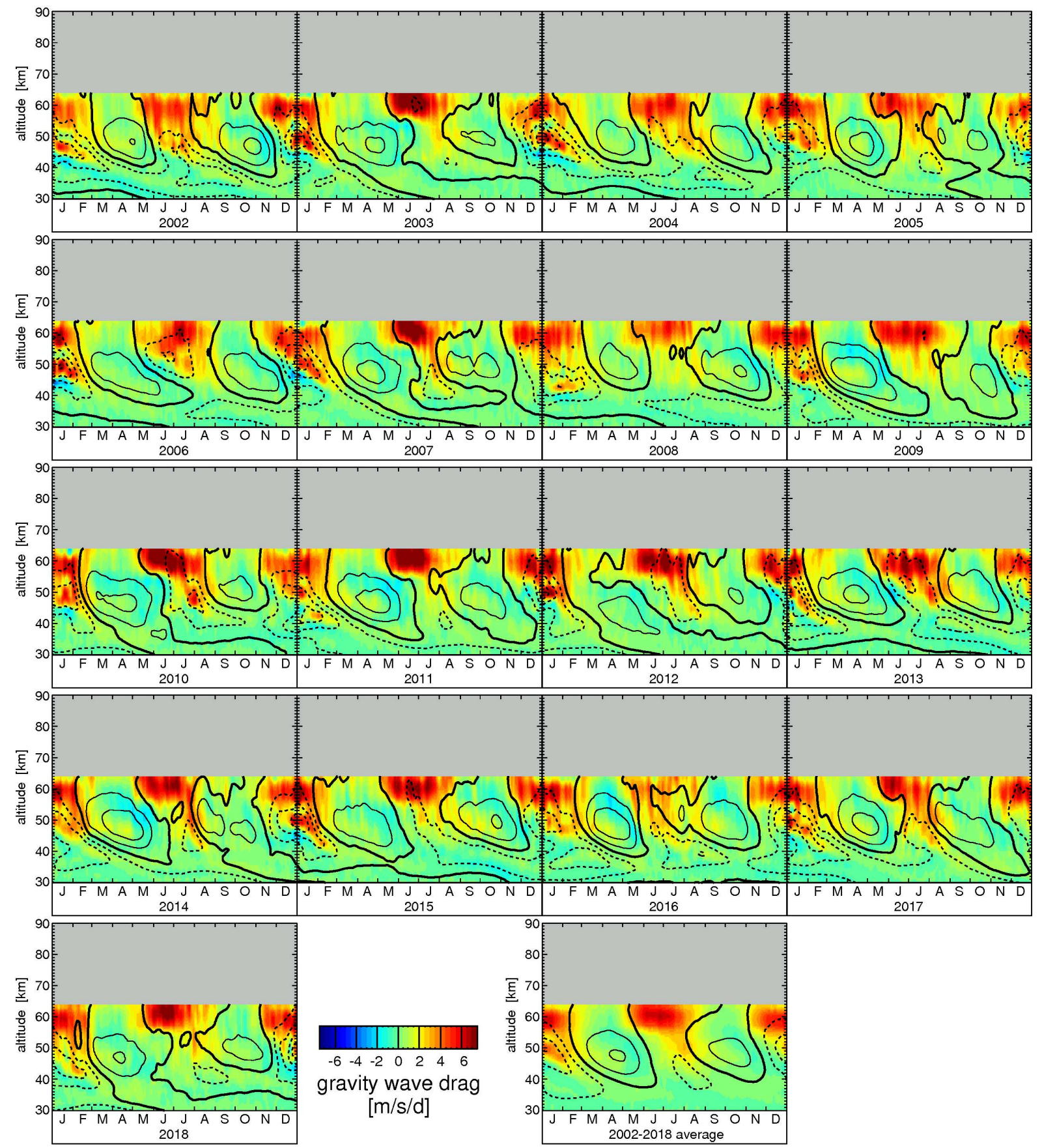

Figure S8. ERA-Interim estimates of zonal total gravity wave drag $\bar{X}_{G W}$ averaged over $10^{\circ} \mathrm{S}-10^{\circ} \mathrm{N}$ for the $2002-2018$ time period, as well as the multi-year average over these years. Overlaid contour lines are ERA-Interim zonal winds averaged over $10^{\circ} \mathrm{S}-10^{\circ} \mathrm{N}(\mathrm{see}$ Fig $\mathrm{S} 2$ ). Contour line increment is $20 \mathrm{~m} \mathrm{~s}^{-1}$. The zero line is highlighted in bold solid, and westward (eastward) zonal wind is indicated by dashed (solid) contour lines. 


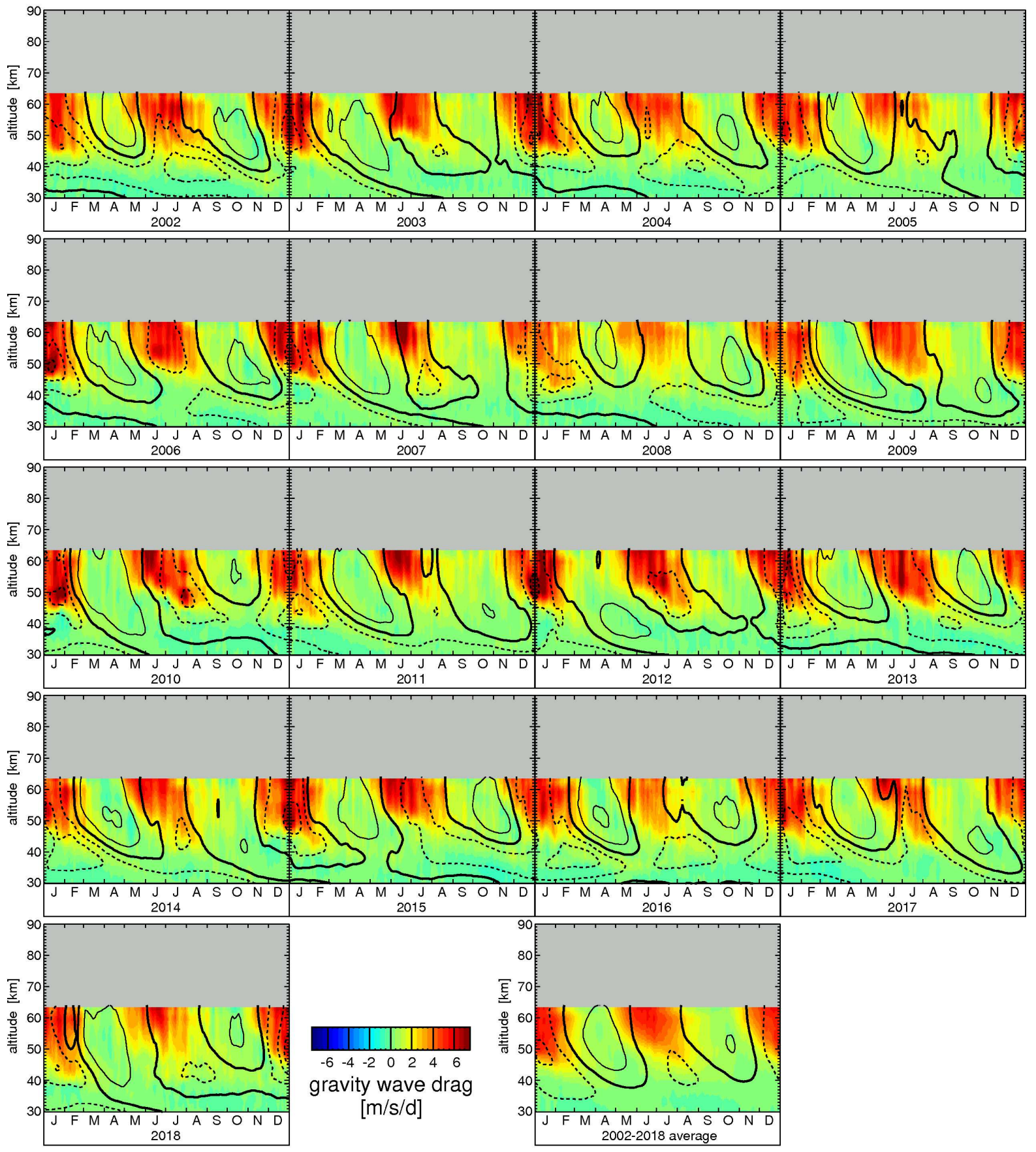

Figure S9. Same as Fig. S8, but zonal total gravity wave drag for JRA-55, overlaid with contour lines of JRA-55 winds (see Fig S3). 


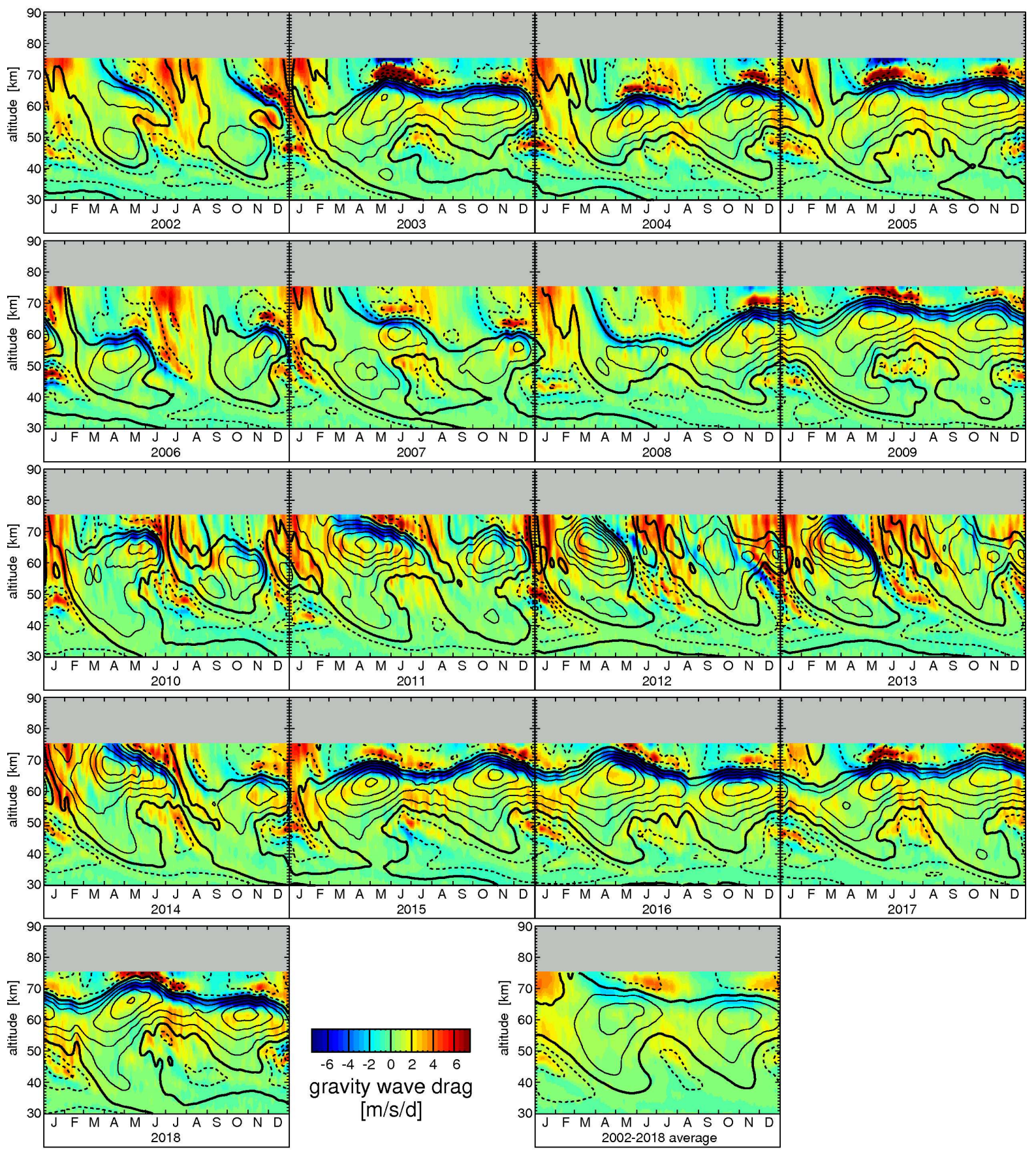

Figure S10. Same as Fig. S8, but zonal total gravity wave drag for ERA-5, overlaid with contour lines of ERA-5 winds (see Fig S4). 

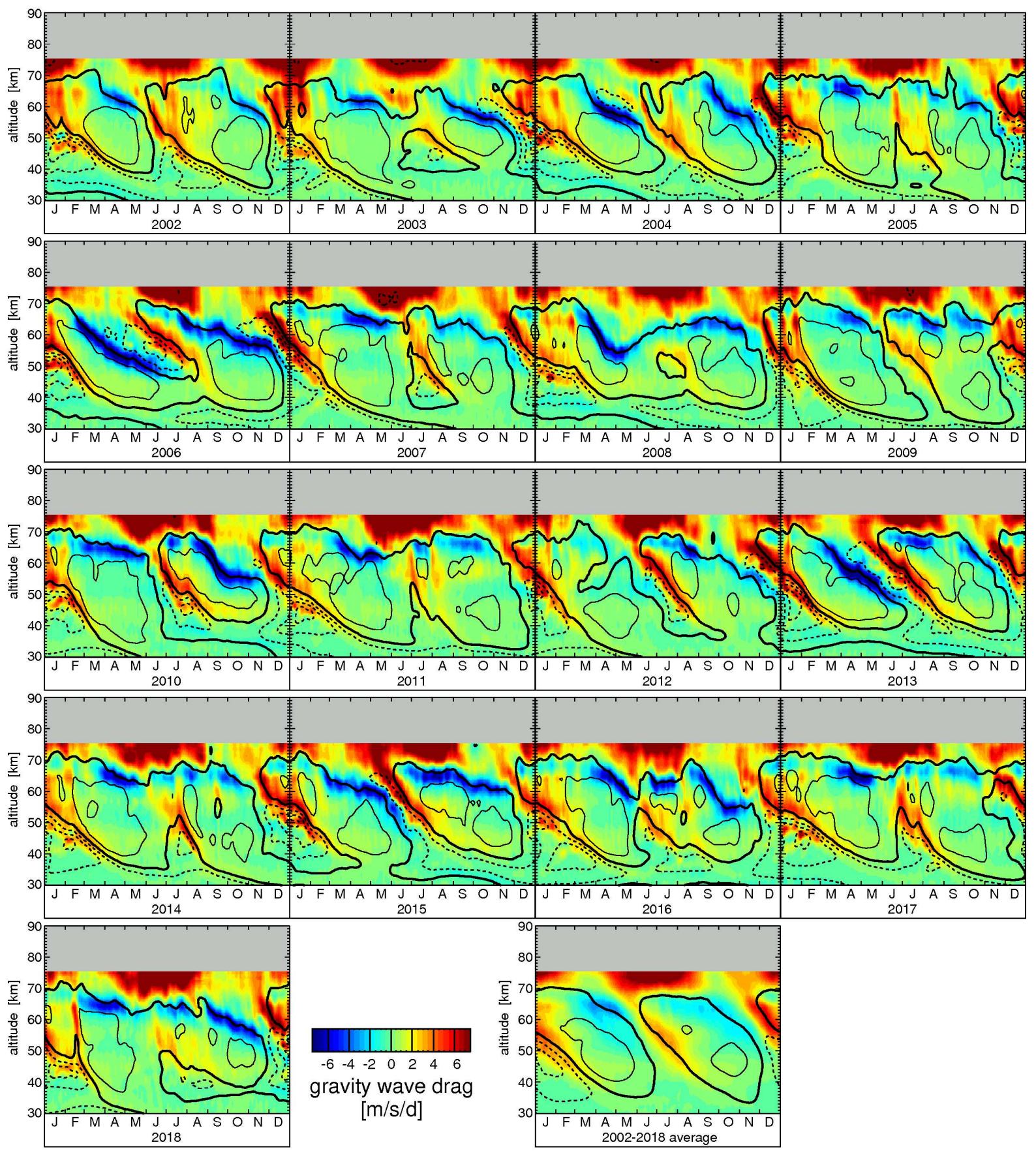

Figure S11. Same as Fig. S8, but zonal total gravity wave drag for MERRA-2, overlaid with contour lines of MERRA-2 winds (see Fig S5). 

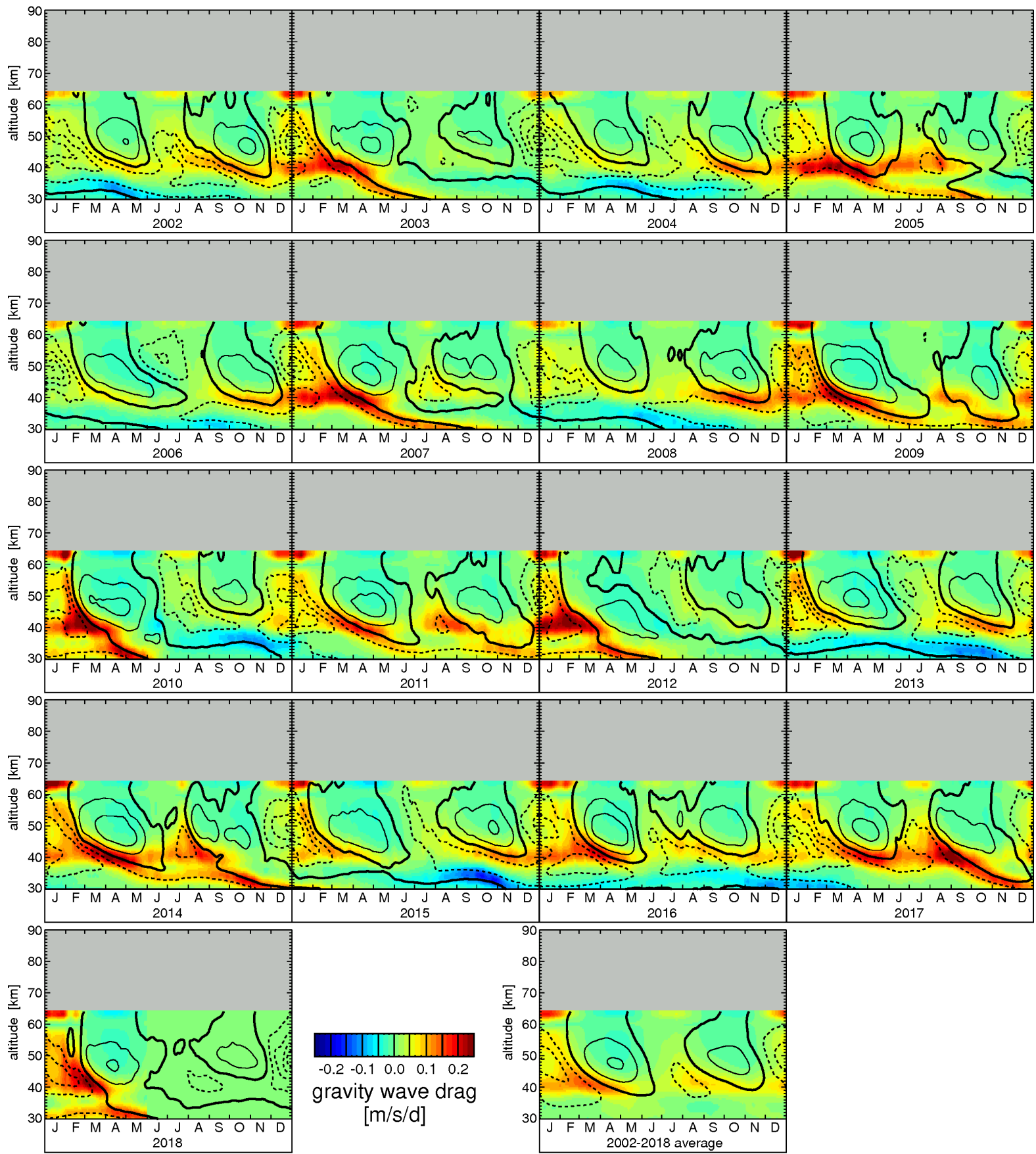

Figure S12. ERA-Interim estimates of model-resolved zonal gravity wave $\operatorname{drag} \bar{X}_{r e s}(k>20)$ averaged over $10^{\circ} \mathrm{S}-10^{\circ} \mathrm{N}$ for the $2002-2018$ time period, as well as the multi-year average over these years. Overlaid contour lines are ERA-Interim zonal winds averaged over $10^{\circ} \mathrm{S}-$ $10^{\circ} \mathrm{N}$ (see Fig S2). Contour line increment is $20 \mathrm{~m} \mathrm{~s}^{-1}$. The zero line is highlighted in bold solid, and westward (eastward) zonal wind is indicated by dashed (solid) contour lines. 

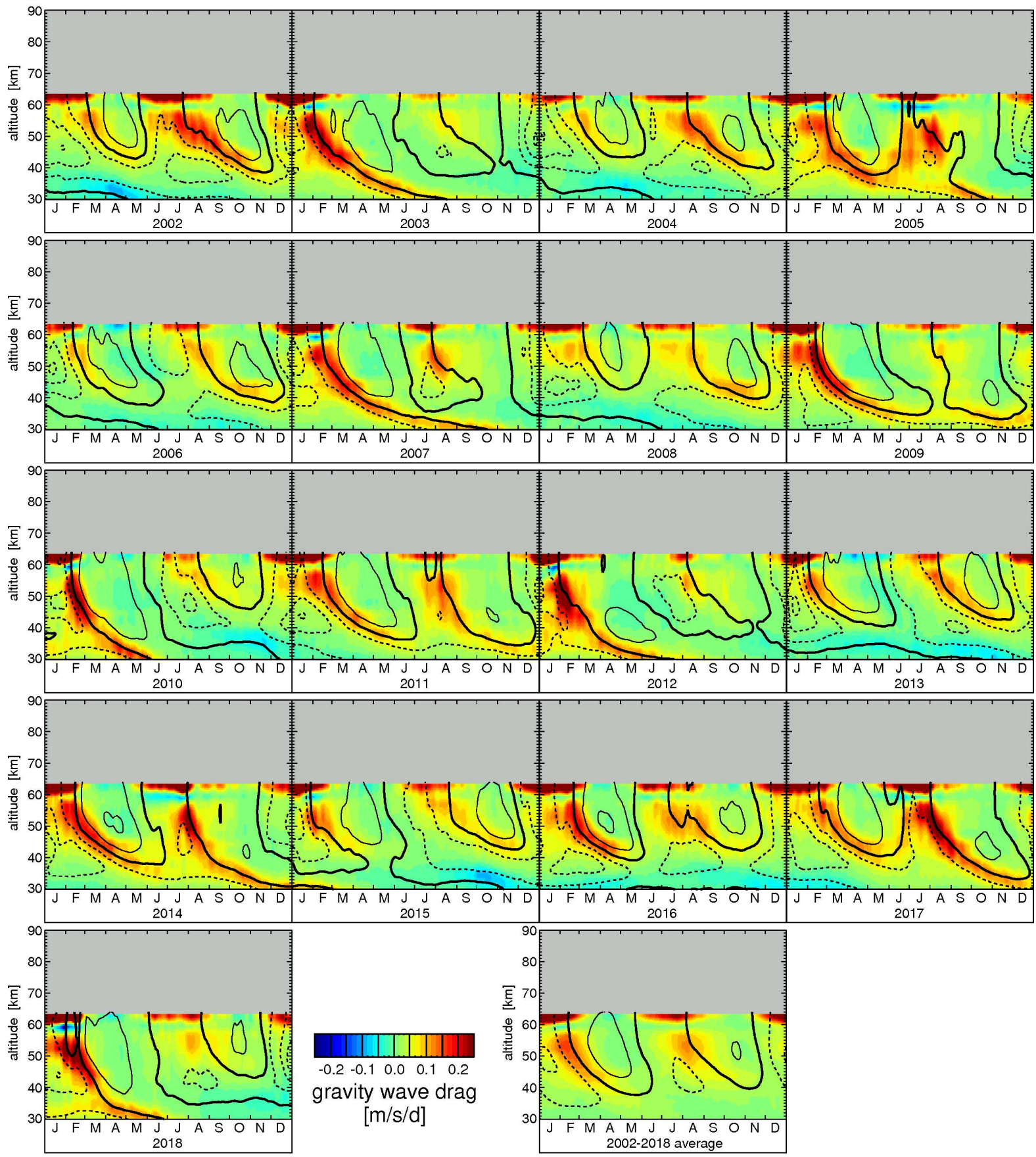

Figure S13. Same as Fig. S12, but model-resolved zonal gravity wave drag $\bar{X}_{r e s}(k>20)$ for JRA-55, overlaid with contour lines of JRA-55 winds (see Fig S3). 


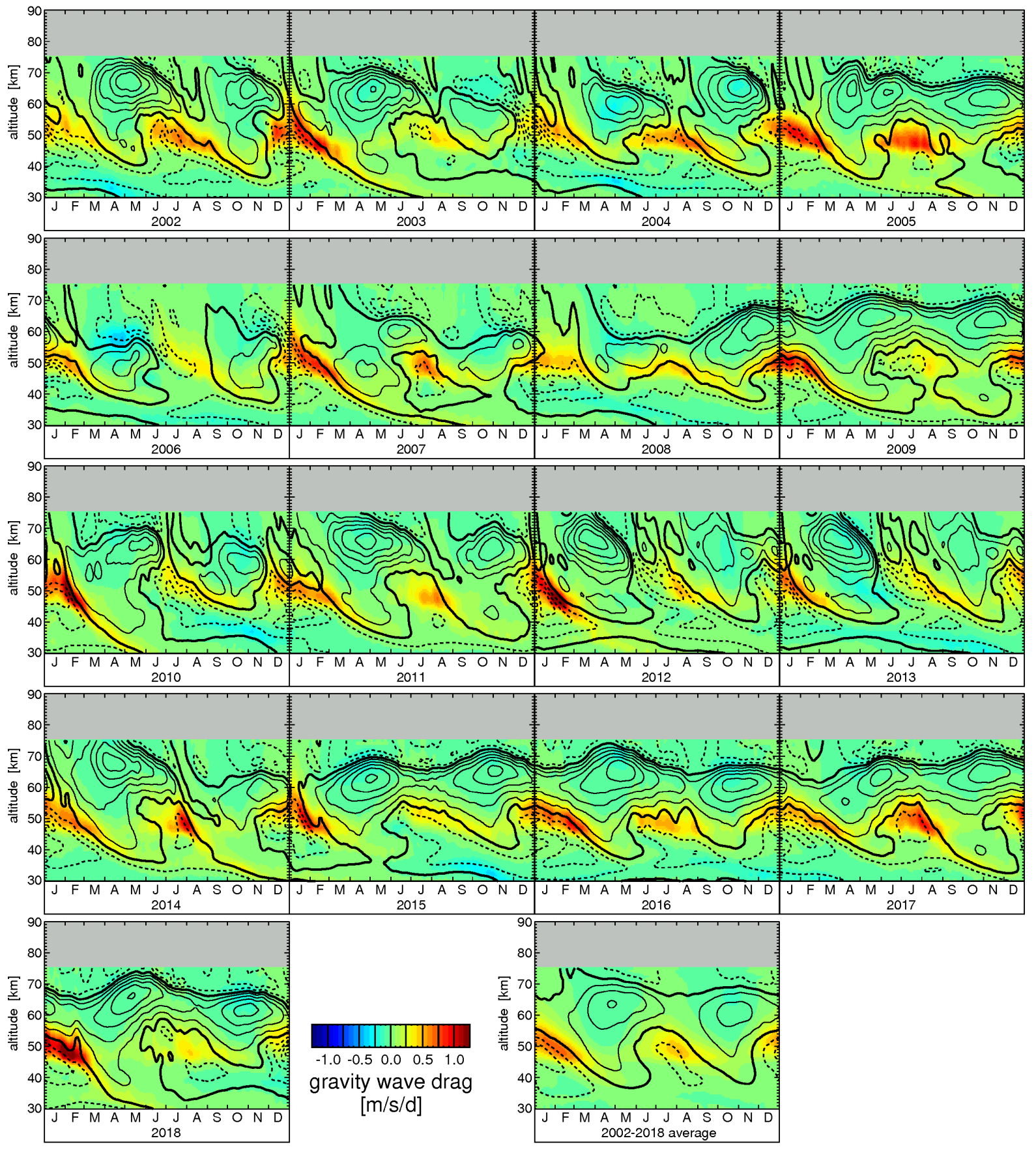

Figure S14. Same as Fig. S12, but model-resolved zonal gravity wave drag $\bar{X}_{r e s}(k>20)$ for ERA-5, overlaid with contour lines of ERA-5 winds (see Fig S4). 


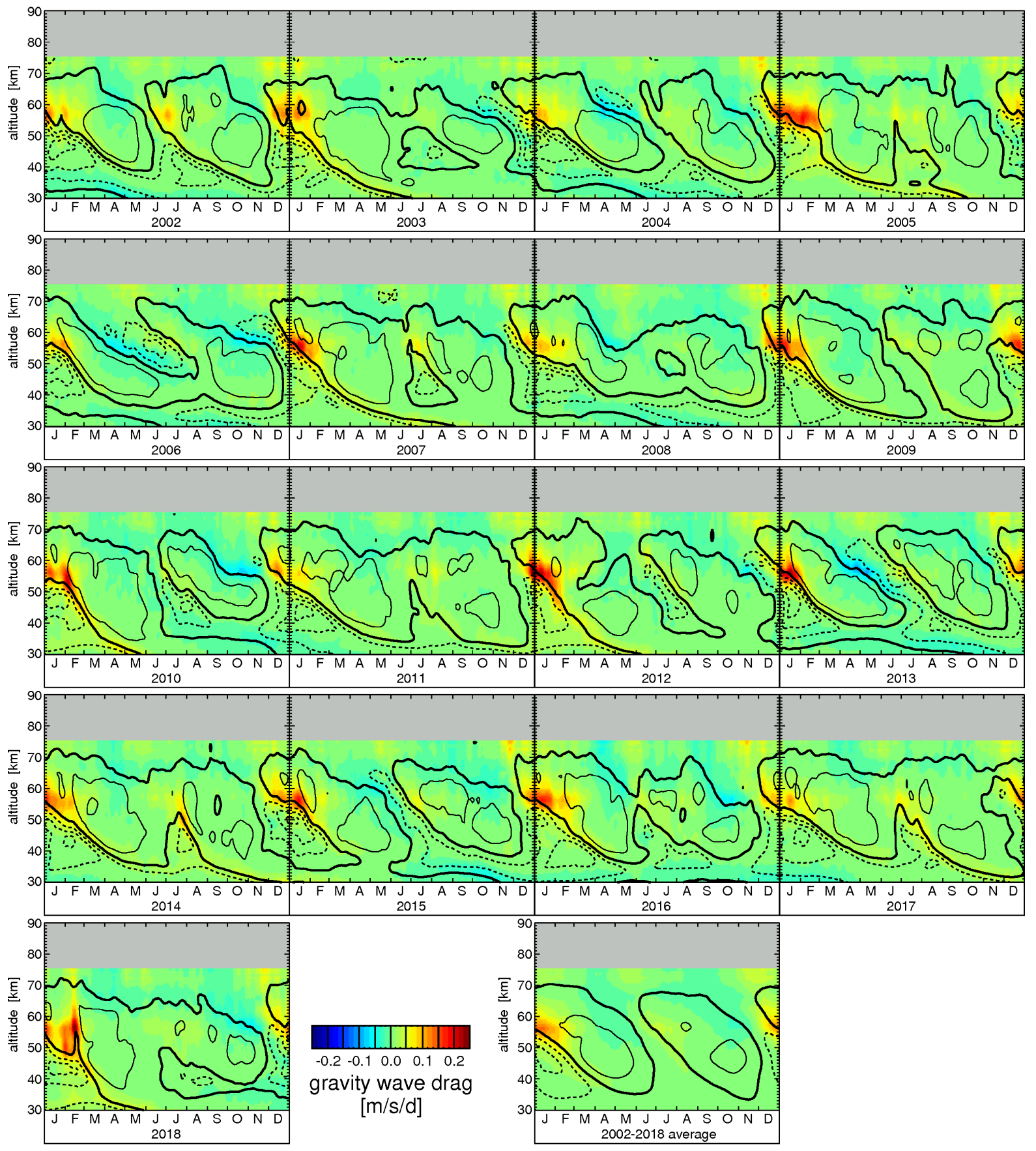

Figure S15. Same as Fig. S12, but model-resolved zonal gravity wave drag $\bar{X}_{r e s}(k>20)$ for MERRA-2, overlaid with contour lines of MERRA-2 winds (see Fig S5). 

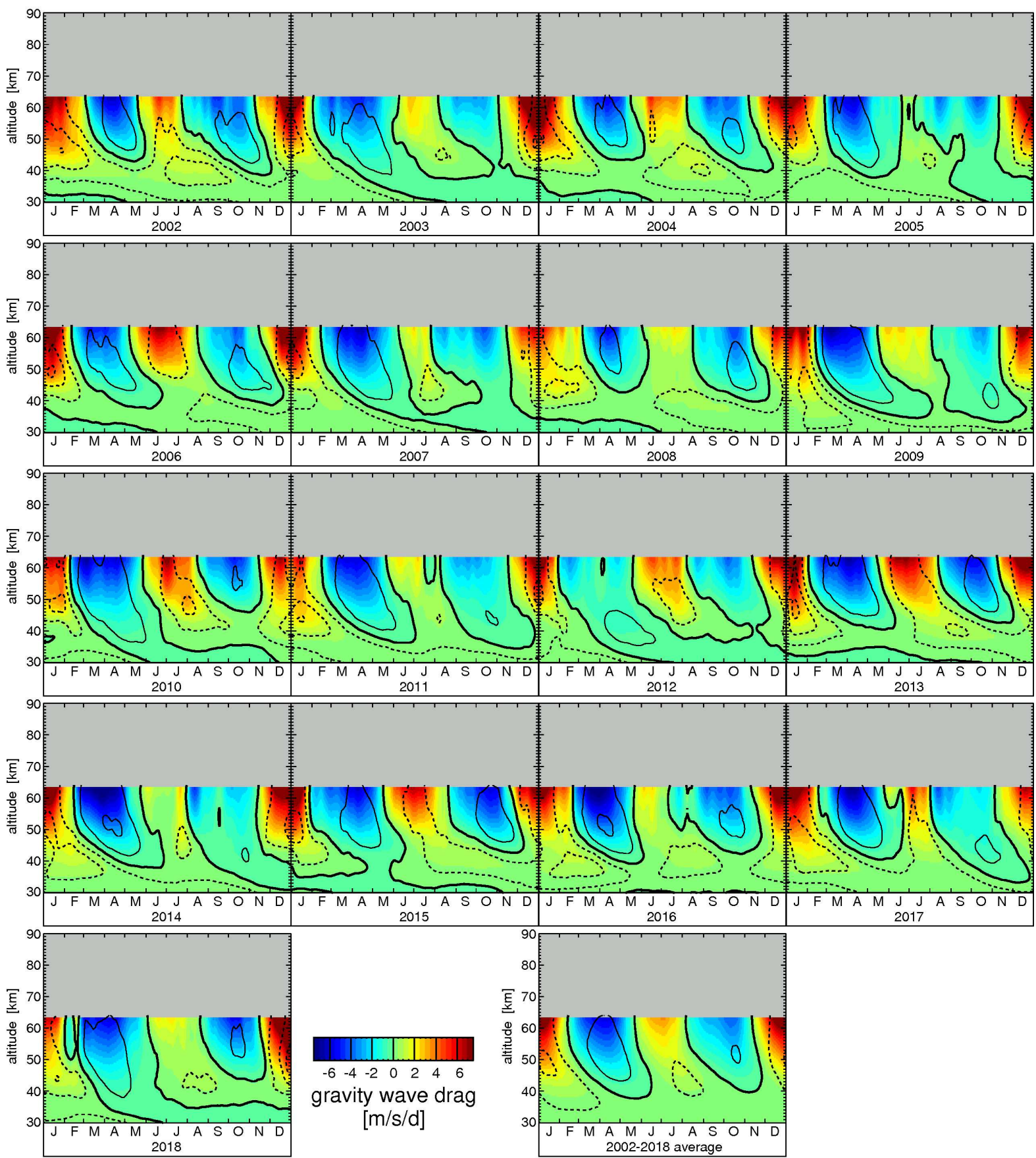

Figure S16. JRA-55 estimates of parameterized zonal gravity wave drag $\bar{X}_{\text {param }}$ averaged over $10^{\circ} \mathrm{S}-10^{\circ} \mathrm{N}$ for the $2002-2018$ time period, as well as the multi-year average over these years. Overlaid contour lines are JRA-55 zonal winds averaged over $10^{\circ} \mathrm{S}-10^{\circ} \mathrm{N}$ (see Fig S3). Contour line increment is $20 \mathrm{~m} \mathrm{~s}^{-1}$. The zero line is highlighted in bold solid, and westward (eastward) zonal wind is indicated by dashed (solid) contour lines. 

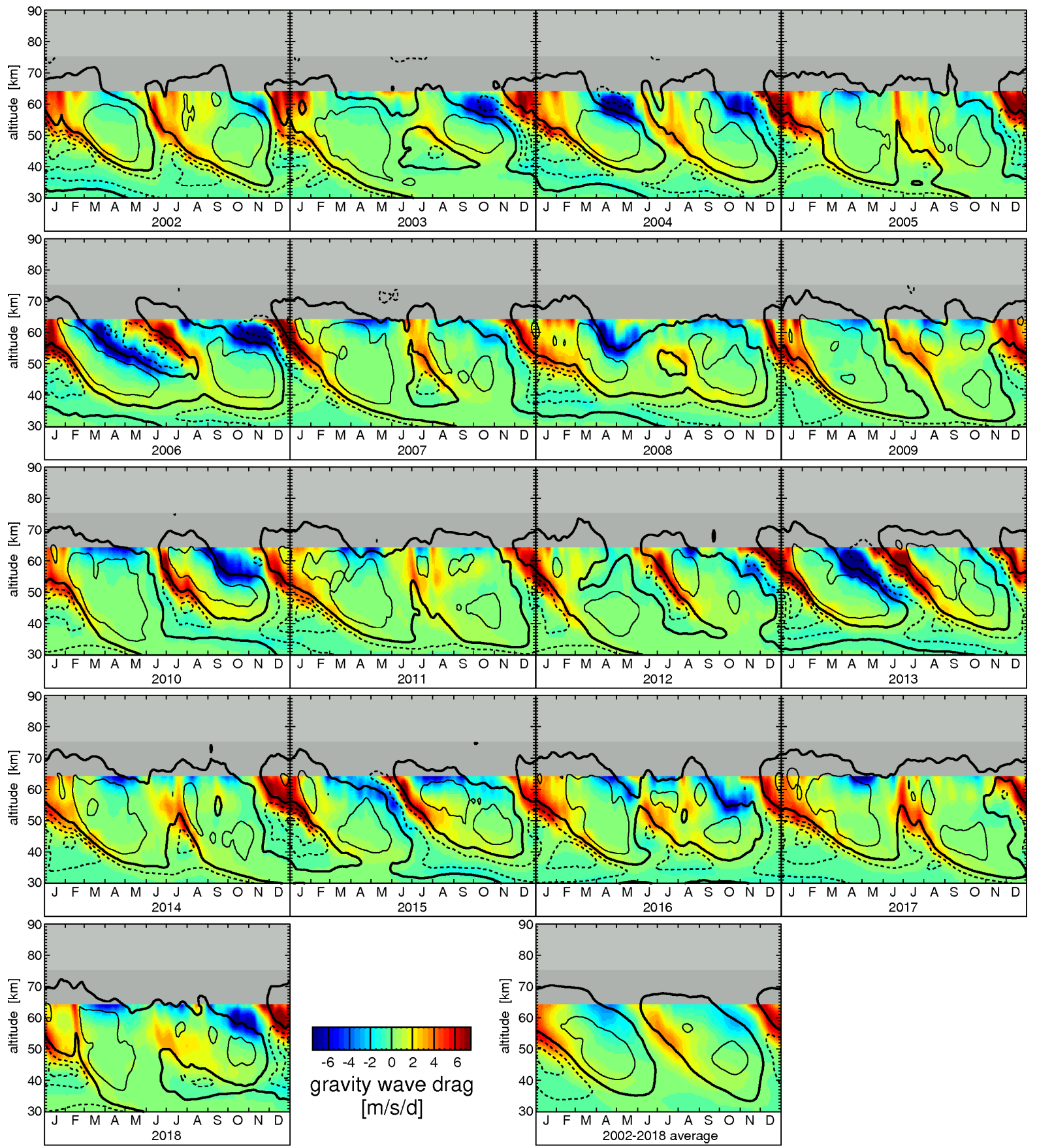

Figure S17. Same as Fig. S16, but parameterized zonal gravity wave drag $\bar{X}_{\text {param }}$ for MERRA-2, overlaid with contour lines of MERRA-2 winds (see Fig S5). 

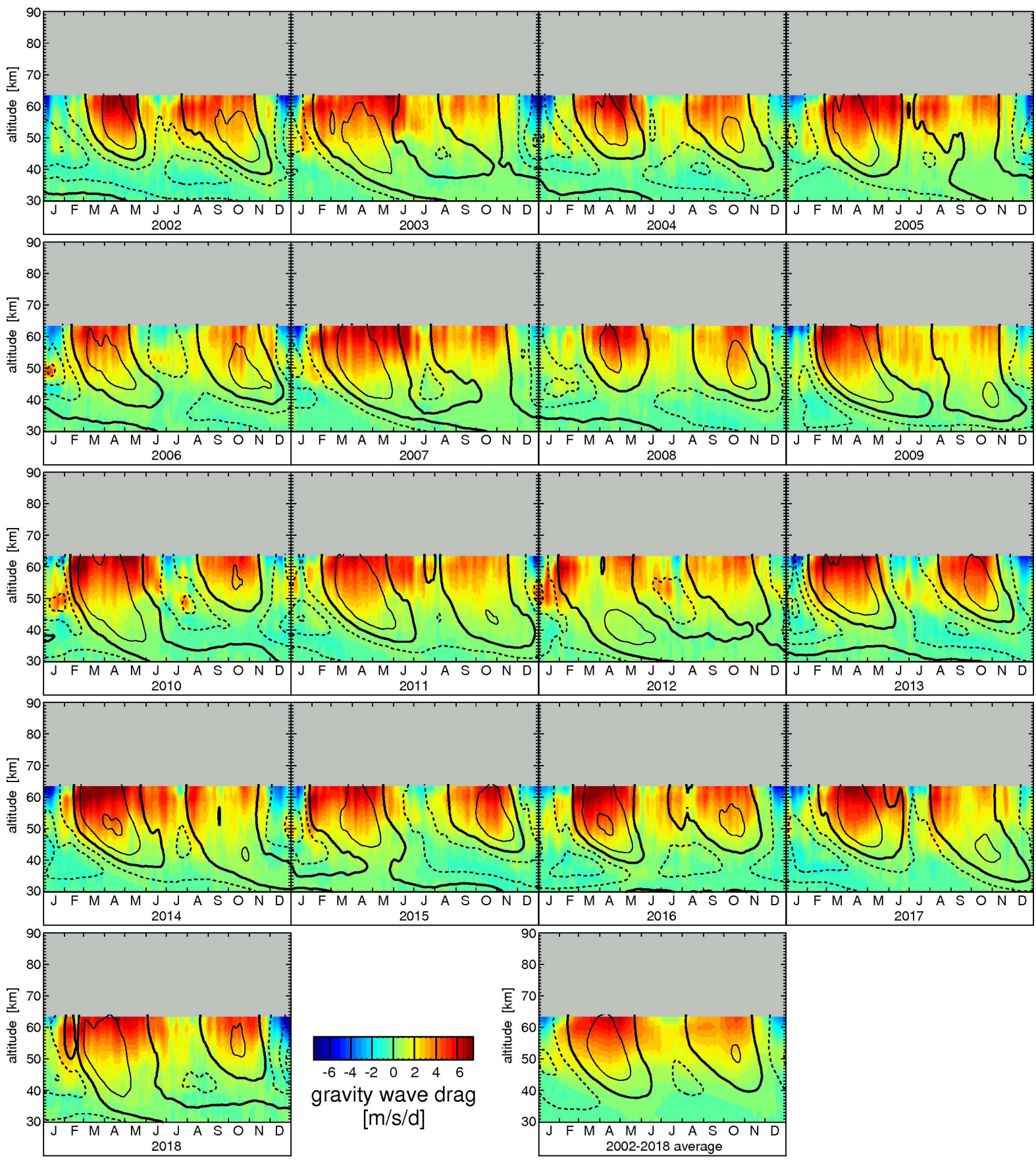

Figure S18. JRA-55 estimates of the imbalance contribution $\bar{X}_{\text {imbalance }}$ to the total gravity wave drag averaged over $10^{\circ} \mathrm{S}-10^{\circ} \mathrm{N}$ for the 2002-2018 time period, as well as the multi-year average over these years. Overlaid contour lines are JRA-55 zonal winds averaged over $10^{\circ} \mathrm{S}-10^{\circ} \mathrm{N}$ (see Fig S3). Contour line increment is $20 \mathrm{~m} \mathrm{~s}^{-1}$. The zero line is highlighted in bold solid, and westward (eastward) zonal wind is indicated by dashed (solid) contour lines. 


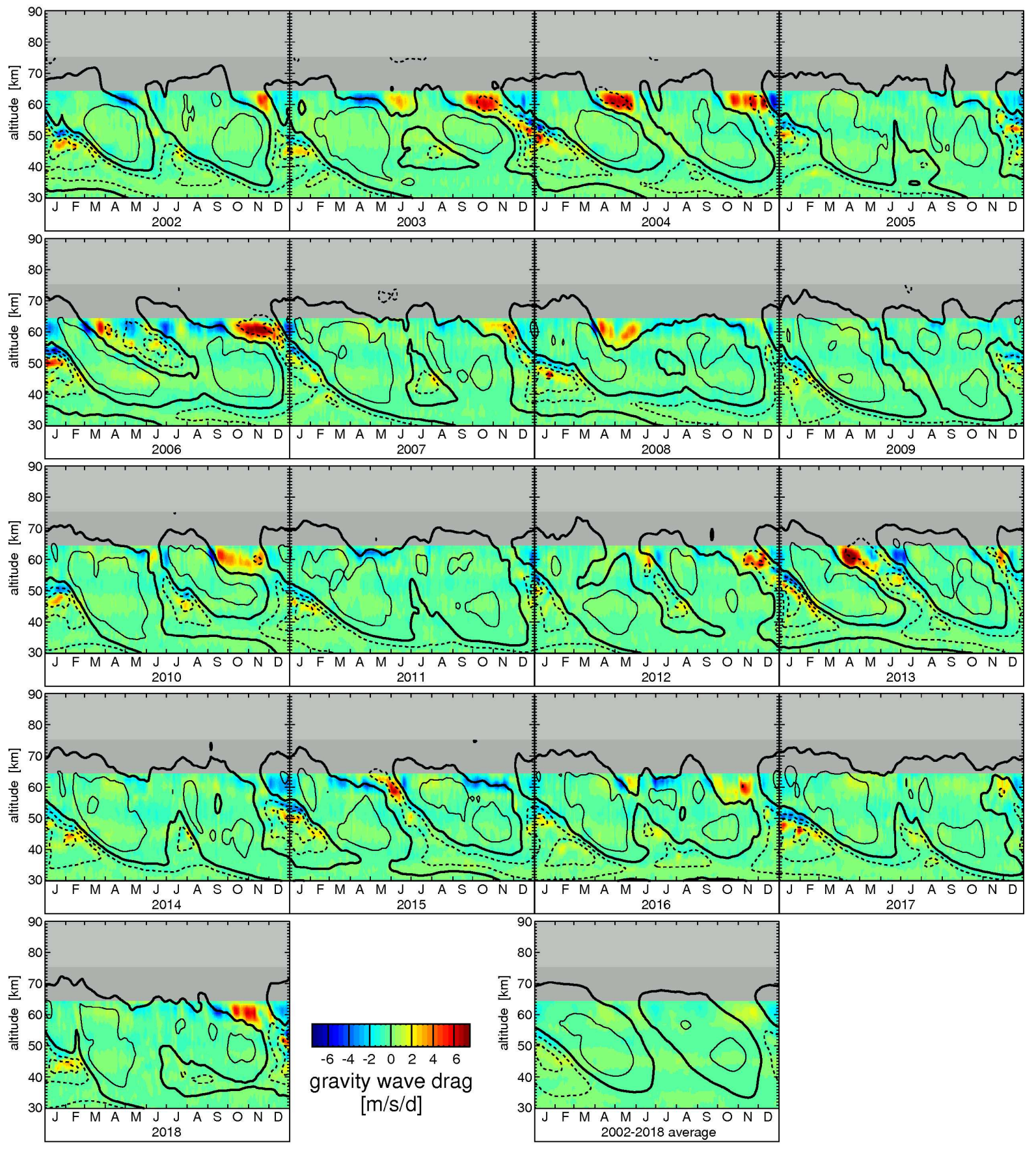

Figure S19. Same as Fig. S18, but the imbalance contribution $\bar{X}_{\text {imbalance }}$ for MERRA-2, overlaid with contour lines of MERRA-2 winds (see Fig S5). 

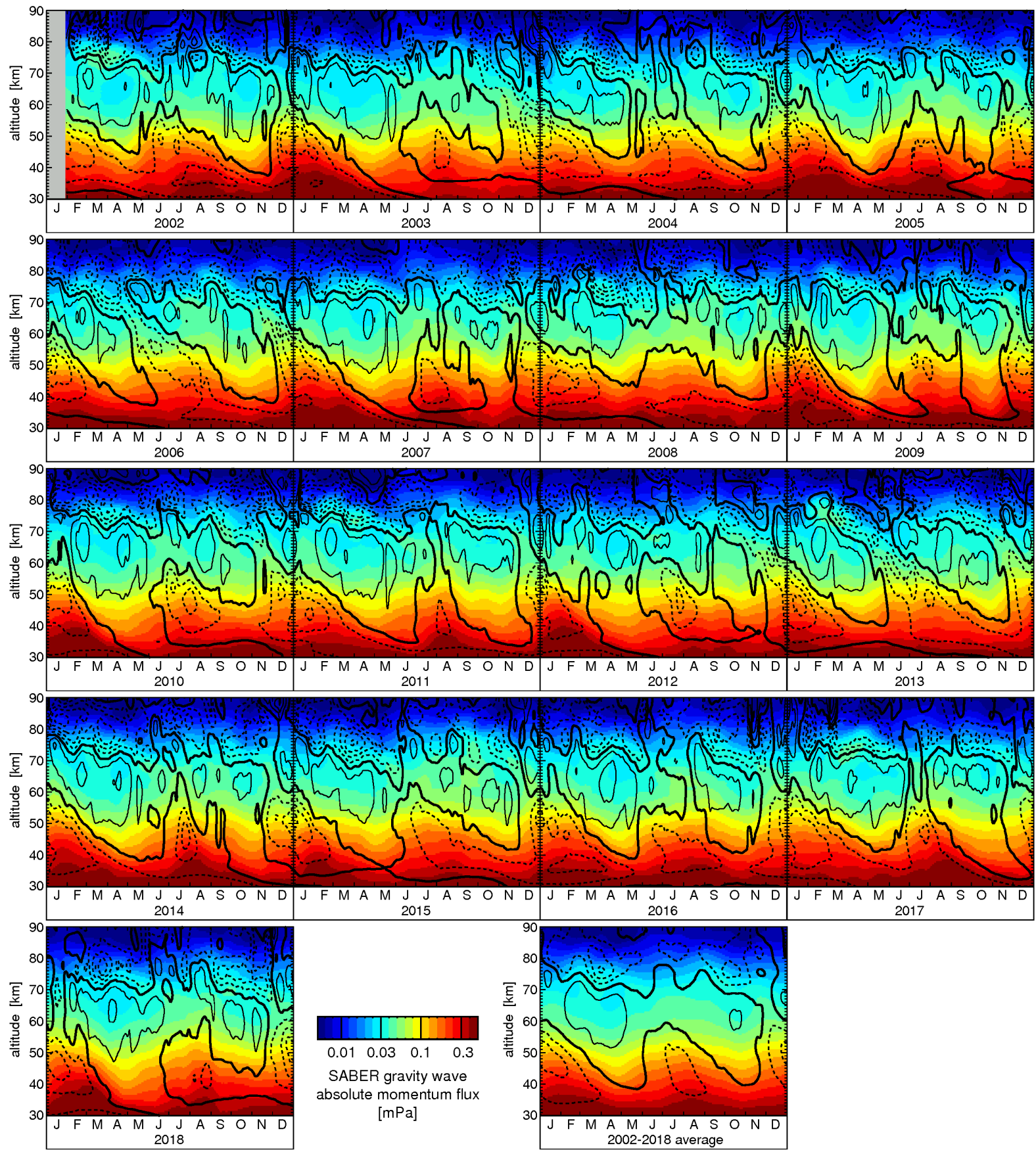

Figure S20. SABER absolute gravity wave momentum flux in $\mathrm{mPa}$ on a logarithmic scale for the 2002-2018 time period averaged over the latitude band $10^{\circ} \mathrm{S}-10^{\circ} \mathrm{N}$, and the average over these years (lower right panel). Contour lines are zonal-average zonal winds of the merged data set based on ERA-Interim, SABER, and TIDI (E/S/T-winds), as described in the main paper. 


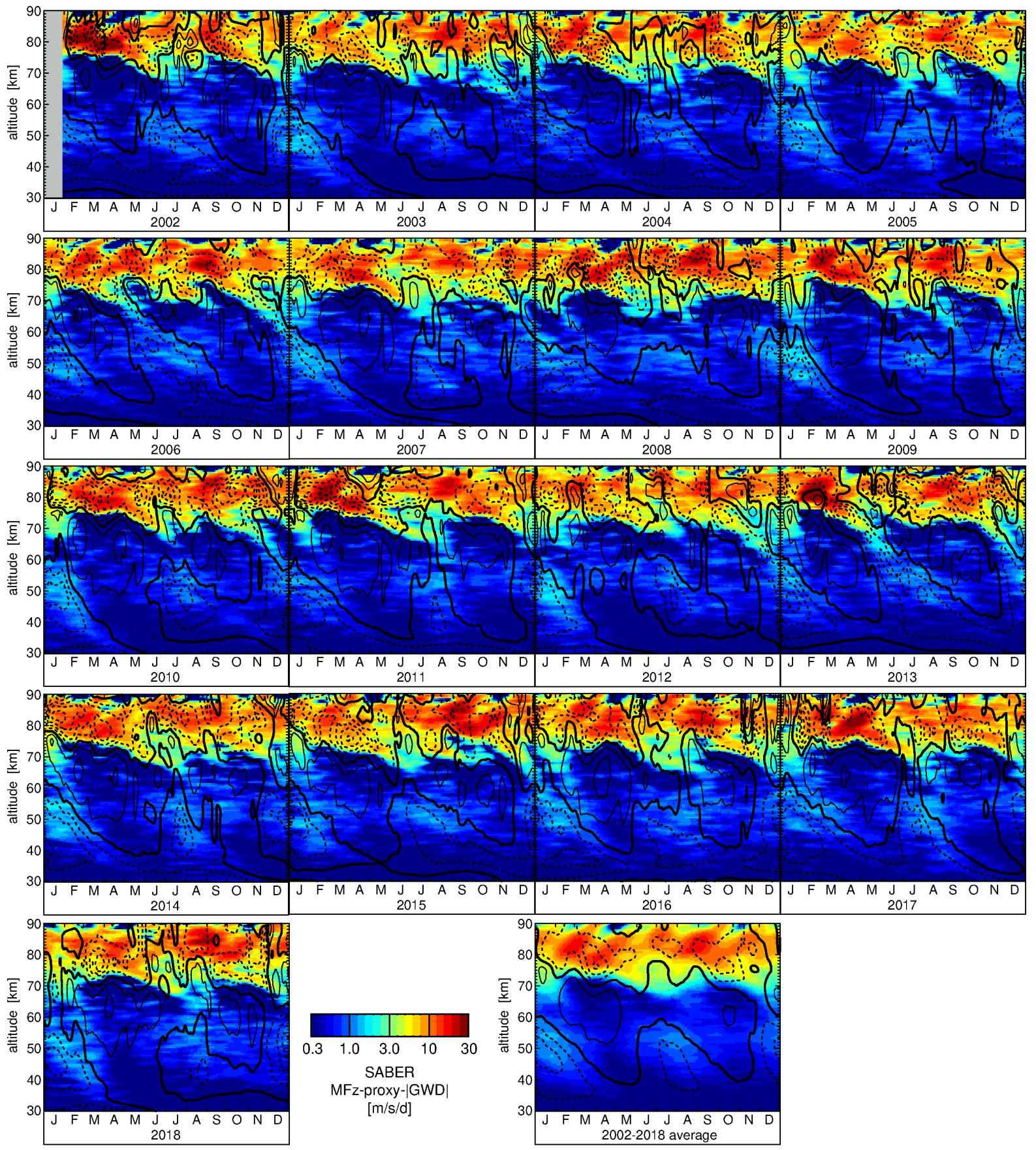

Figure S21. SABER proxy for absolute gravity wave drag (MFz-proxy- $|\mathrm{GWD}|$ ) obtained from vertical gradients of absolute momentum flux normalized by the negative background density. Values are in $\mathrm{m} \mathrm{s}^{-1} \mathrm{~d}^{-1}$ on a logarithmic scale. Values are shown for the $2002-2018$ time period averaged over the latitude band $10^{\circ} \mathrm{S}-10^{\circ} \mathrm{N}$, as well as the average over these years (lower right panel). Contour lines are zonal-average zonal winds of the merged data set based on ERA-Interim, SABER, and TIDI (E/S/T-winds), as described in the main paper. 

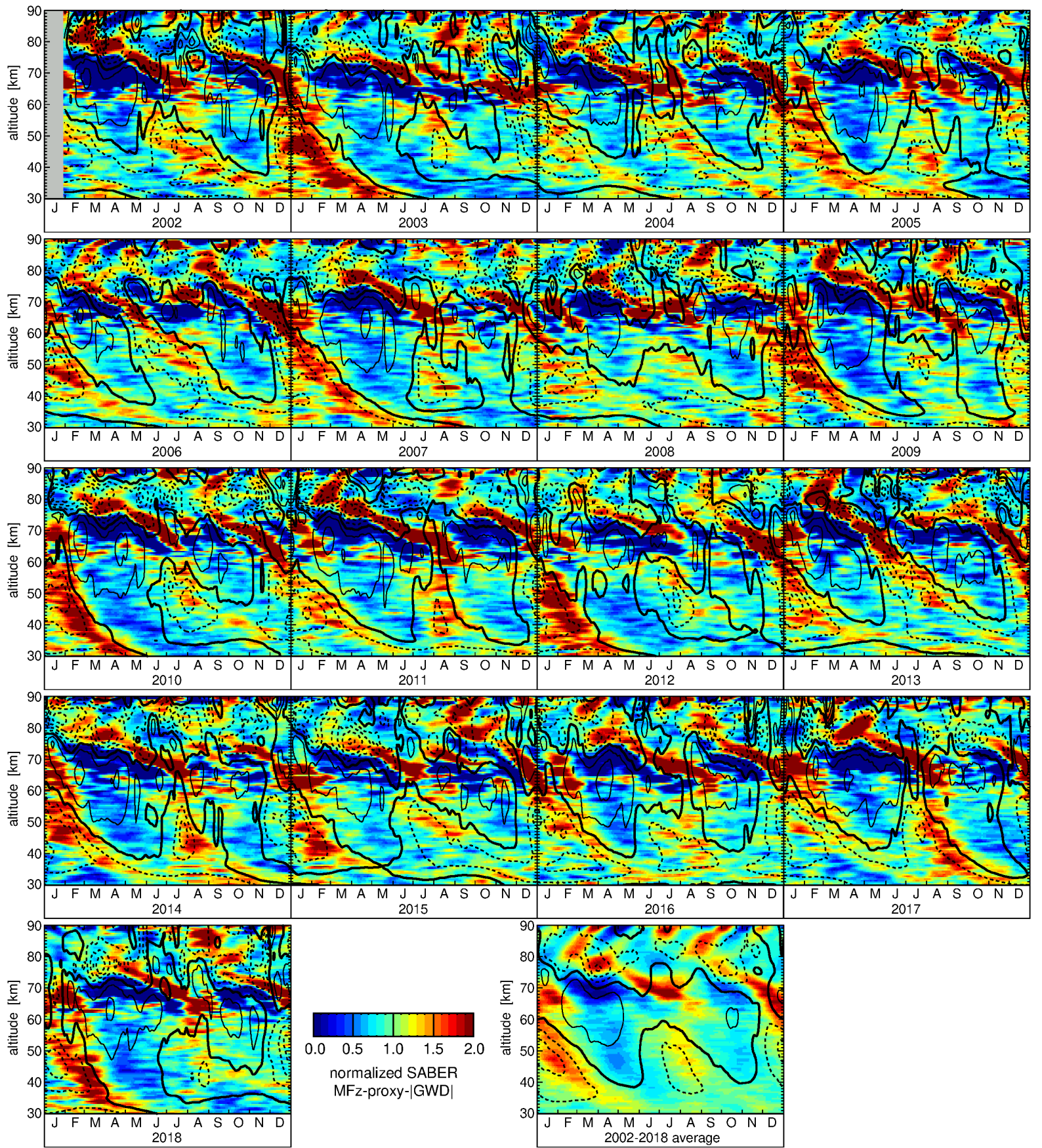

Figure S22. Same as Fig. S21, but values are normalized by the annual average, separately for each year and altitude. 

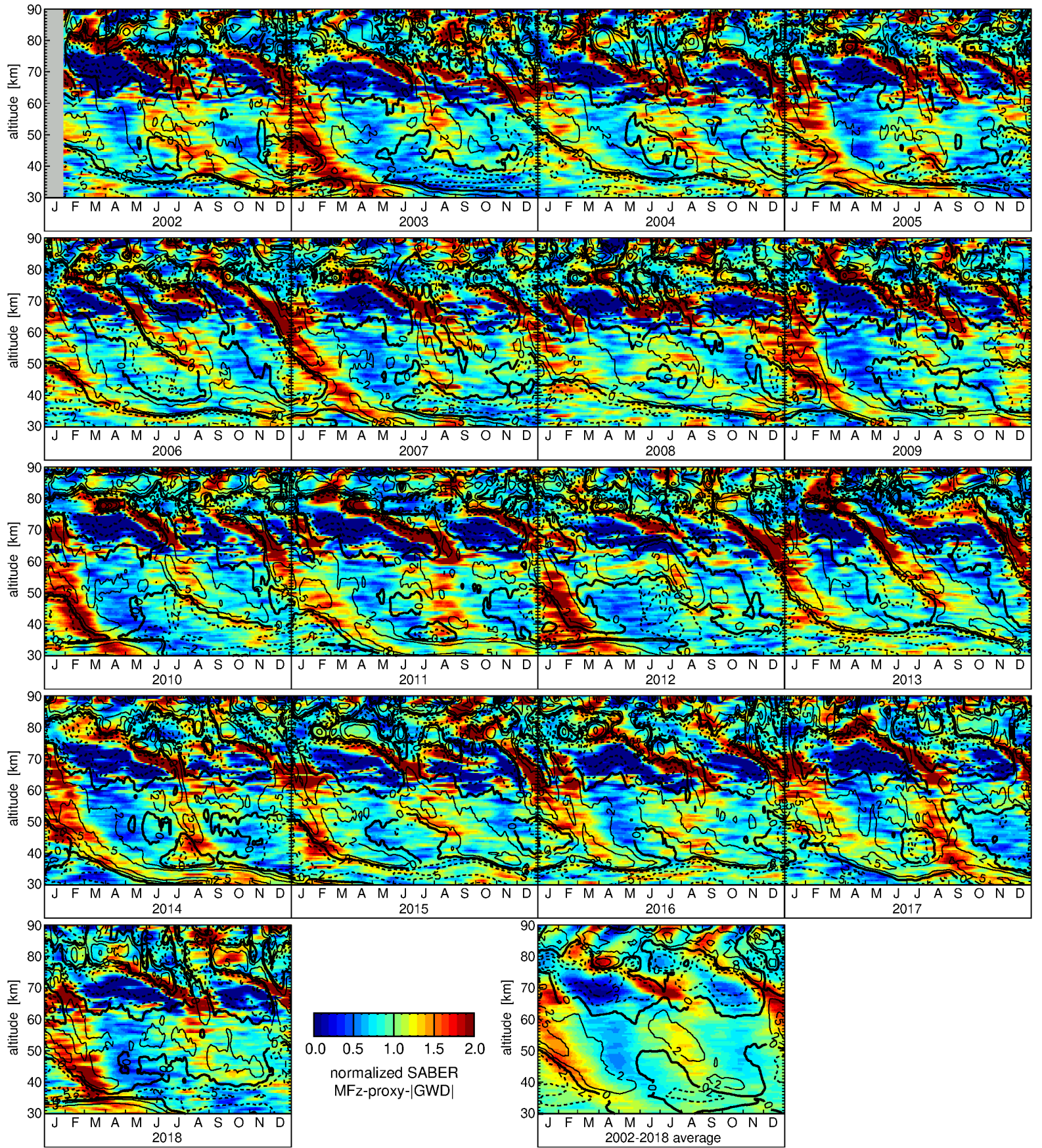

Figure S23. Same as Fig. S22, but contour lines are the vertical gradient of zonal-average zonal winds of the merged data set based on ERA-Interim, SABER, and TIDI ("E/S/T-winds"), as described in the main paper. Contour lines are at $0, \pm 2, \pm 5$, and $\pm 10 \mathrm{~m} \mathrm{~s}^{-1} \mathrm{~km}^{-1}$. Westward (=negative) gradients are indicated by dashed contour lines. 

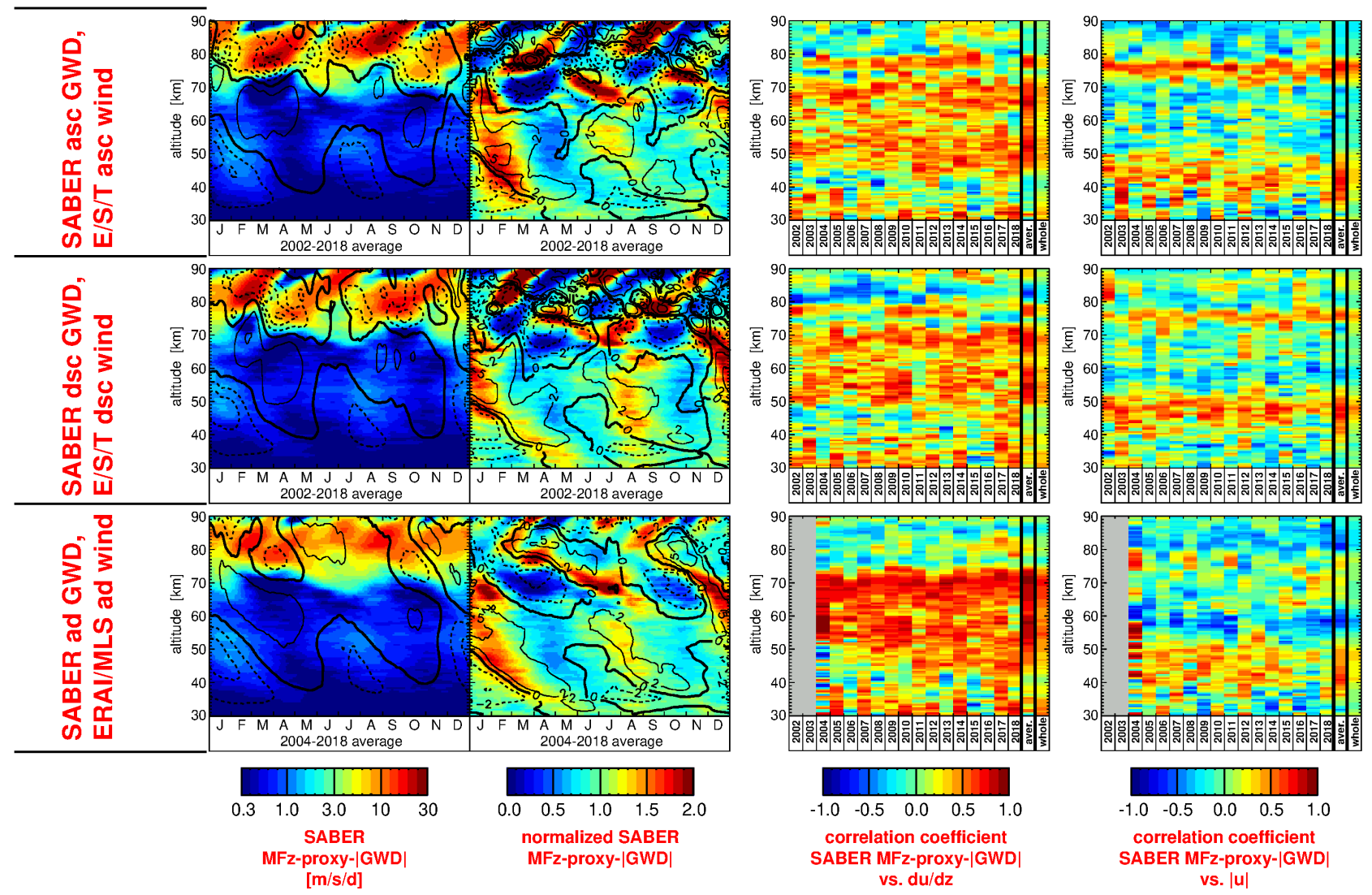

Figure S24. Left column: the SABER MFz-proxy- $|\mathrm{GWD}|$ (a proxy for absolute gravity wave drag) averaged over $10^{\circ} \mathrm{S}-10^{\circ} \mathrm{N}$ and the years 2002-2018 (2004-2018 for MLS), overlaid with zonal wind contour lines of different zonal wind data sets averaged over the same latitudes and period. Second column: Same as left column, but for normalized SABER MFz-proxy-|GWD| overlaid with contour lines of zonal wind vertical gradients. Third column: Temporal correlations between SABER MFz-proxy- $|\mathrm{GWD}|$ and zonal wind vertical gradients, separately for each year, for the multi-year averages, and for the whole time series. Right column: Same as third column, but for the correlation between SABER MFz-proxy- $\mid$ GWD $\mid$ and zonal wind absolute values. The different rows are (from top to bottom) for (1) the merged ERA-Interim, SABER and TIDI data set as described in Sect. 4.2.3 of the main paper, but here only for ascending orbit legs, (2) same as (1), but only for descending orbit legs, and (3) the merged dataset of ERA-Interim and MLS quasi-geostrophic winds as described in Sect. 4.2.2 of the main paper (i.e., averaged over ascending and descending orbit legs). For zonal winds, contour line increment is $20 \mathrm{~ms}^{-1}$. The zero wind line is highlighted in bold solid, and westward (eastward) winds are indicated by dashed (solid) contour lines. 